\title{
Luzes e sombras: a natureza na peregrinação a Santiago de Compostela segundo o Codex Calixtinus (século XII)
}

\author{
Lorena da Silva Vargas ${ }^{l}$
}

Resumo: No sacrifício da peregrinação medieval, os fiéis encontram um meio de alcance espiritual consigo e com Deus. Pelo caminho, a natureza revela-se escudeira e desafiadora dos limites humanos, carregada de atributos religiosos em um momento de advento da Filosofia Natural. Neste artigo, analisaremos a atuação do ambiente natural na peregrinação a Santiago de Compostela no século XII a partir do CodexCalixtinus, especificamente a partir de seu livro $\mathrm{V}$, o Guia do Peregrino. Enquanto um dos primordiais guias medievais, o Guia do Peregrino não apenas faz uma descrição da natureza no caminho, mas apresenta o conteúdo simbólico que a mesma revela no período.

Palavras-chave: natureza, peregrinação, Santiago de Compostela.

Abstract:In the sacrifice of medieval peregrination, the faithful find a form of spiritual meeting with themselves and God. By the way, the nature reveals itself as an ally and challenging of the human limits, full of religious attributes in a moment of advent of the Natural Philosophy. In this article, will be analyzed the actuation of the natural ambient in the peregrination to Santiago de Compostela in the XII century from Codex Calixtinus, specifically from the fifth book, the Peregrines' Guide. While an of the firsts medieval guides, the Peregrines' Guide don't just make a description about the nature in the way, but presents the symbolic contend that it reveals in that period.

Keywords: nature, peregrination, Santiago de Compostela.

A natureza foi palco, ao longo dos séculos, de fatos que marcaram a vida humana, tanto em seu campo evolutivo propriamente, quanto em suas relações sociais e na formação urbana. O ambiente está ligado intrinsicamente ao homem e às suas modificações no meio, fornecendo-lhe muito mais que o essencial à sobrevivência: a dimensão

\footnotetext{
${ }^{1}$ Mestranda em História pela Universidade Federal de Goiás - UFG/CNPq.

E-mail: lorenasvargas@hotmail.com.
}

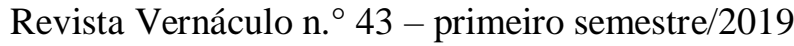

ISSN $2317-4021$ 
ambiental é "parte constitutiva da história.", Vale ressaltar que essa presença vai além das funções físicas utilitárias, de sustento e habitação, por exemplo; compreende-se como templo para os gregos antigos, fazendo parte também do imaginário social e religioso, servindo ainda de fundamento para teorias como o monismo de Tales de Mileto (624 a.C. - 546 a.C.),segundo a qual tudo no universo seria composto por água, o que revelaria o embasamento filosófico e cientifico na percepção do natural.

Durante a Idade Média a utilização do ambiente natural não foi menos intensa que nos séculos que a precederam, agindo sobre os homens igualmente em suas vitórias e desventuras ao servir, por exemplo, de abrigo a fugitivos de guerra ao mesmo tempo em que fornecia ferramentas para estratégias bélicas do exército inimigo, como o desvio de água dos rios de um vilarejo a fim de prejudicar, com a seca, os adversários ali alojados. Convém destacar ainda a presença do natural ao longo da peregrinação a Santiago de Compostela, cuja origem data do final do século IX, analisando a contribuição ambiental na jornada. O livro V do Liber Sancti Iacobi, ou Codex Calixtinus obra escrita por volta de 1160 e atribuída ao Papa Calisto II corresponde ao Guia do Peregrino, encomendado a Aymerico Picaud e,correspondendo a um dos primeiros guias do Ocidente, dedicou-se aos peregrinos que partiam das mais distintas regiões da Europa em direção

2 CARVAlHO, Alessandra Izabel de, LAVERDI, Robson, SILVA, Danusa de Lourdes Guimarães da. A dimensão ambiental do conhecimento histórico: entrevista com José Augusto Pádua, Revista de História Regional. 19(2): 457-484, 2014, p. 462.

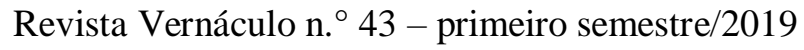

ISSN 2317-4021 
à remissão que o apóstolo Tiago lhes traria ao fim do caminho, em Compostela. O Guia do Peregrino informa ao viajante a situação dos caminhos, seu grau de dificuldade, bem como as cidades, povos e rios que devem ser evitados, a fim de alertar os caminhantes sobre os perigos que se fazem presentes no trajeto.

As análises aqui apresentadas dirão respeito ainda à construção do imaginário na vida e morte de São Tiago Maior, assim como em seu culto sepulcral, passando pela discussão a respeito do translado de seu corpo e a presença dos sinais e símbolos da natureza que a ele se associam e formam, através do maravilhoso, uma nova imagem do homem que se tornou santo.

\section{São Tiago Maior: hagiografia e simbolismo natural}

O ambiente natural se fez presente na vida de São Tiago Maior de tal forma, que terá ampla relevância em seu processo de beatificação. Por meio dos relatos bíblicos, identifica-se a importância especialmente da água no cotidiano catequético do apóstolo, sendo lagos, rios e mares palcos de episódios marcantes na vida de São Tiago. A água em suas múltiplas formas - mares, rios, tempestades - sempre foi temida pelo homem medieval, especialmente por representar o desconhecido, relacionando-a à presença de sereias e monstros, crocodilos e hipopótamos, dilúvios e naufrágios que corresponderiam aos desígnios 
divinos para com os navegantes. ${ }^{3}$ Além disso, diz Aznar Vallejo sobre os perigos da navegação mercantil, referindo-se aos corsários: "Los daños ocasionados por El hombre sobre pasa banen número y gravedad a los provocados por los rigores de la naturaleza."4 . Tal assertiva pode ser considerada ainda no sentido da peregrinação terrestre, uma vez que os perigos humanos, especialmente saques, não eram raros no decorrer do caminho.

Segundo Delumeau ${ }^{5}$, desde a antiguidade não há epopeia sem tempestade. No caso de São Tiago, entretanto, é a maneira pacífica como o mar temível se apresenta frente ao santo que leva à exaltação do apóstolo, digno de respeito ao longo da vida e, especialmente, no episódio do translado de seu corpo de Jerusalém à Galiza, como veremos adiante. Enquanto elemento de simbolismo religioso originalmente pagão, a água serve de herança ao misticismo judaico cristão por seu caráter redentor, purificação associada ao sacramento do batismo. Assim, o Tiago pescador por ofício, passa a ser pescador de homens enquanto discípulo de Cristo, assim como as igrejas passariam a ser uma metáfora da embarcação cristã. O mesmo elemento natural que traz a provação, traz a salvação e, da mesma forma apresenta-se ao peregrino em sua caminhada.

${ }^{3}$ MOLINA MOLINA, Ángel Luis. Los viajes por mar em la Edad Media, Cuadernos de Turismo. 5: 113-122, 2000, p. 121.

${ }^{4}$ AZNAR VALLEJO, Eduardo. El mar: fuente de conflictos y exigencia de paz, Edad Media. 11: 63-89, 2010, p. 77.

${ }^{5}$ DELUMEAU, Jean. El miedoenOccidente. Madrid: Taurus, 2012, p. 50. Apud: LEBRERO COCHO, Jorge. Hidrofobia medieval: miedos y peligros vinculados al água em la literatura castellana del XV, Medievalismo. 25: 261-284, 2015, p. 266.

Revista Vernáculo n. ${ }^{\circ} 43$ - primeiro semestre/2019

ISSN 2317-4021 
As primeiras narrativas que dizem respeito à vida de São Tiago estão contidas no livro sagrado cristão e, segundo é relatado, Tiago teria sido pescador, crescendo às margens de rios e lagos e auxiliando o pai no ofício. O próprio chamado de Jesus a Tiago e a seu irmão João teria ocorrido à beira do mar da Galileia enquanto consertavam suas redes. ${ }^{6}$ Quanto à morte do apóstolo, há controvérsias, em especial com relação ao translado de seu corpo. No Liber Sancti Iacobi encontram-se algumas referências que tratam do assunto. De acordo com o Papa Calisto em seu prólogo, nove dos discípulos de São Tiago, que teriam recebido seu chamado na Hispania, afirmam que após a morte de Jesus os apóstolos saíram pelo mundo em pregação, sendo que Tiago fora enviado à Hispania. ${ }^{7}$ Sequencialmente, o papa afirma que pouco antes de sua morte Tiago retorna a Jerusalém, onde é morto. No entanto, em uma carta do Papa Leão, também presente no Codex Calixtinus, nada é citado a respeito da ida do apóstolo à Hispania ainda em vida, tomando por base que três de seus discípulos haviam sido escolhidos em Jerusalém, reconhecendo, portanto, a presença do apóstolo naquela região. ${ }^{8}$

O ponto principal de análise a ser abordado a respeito do translado, seria a condição da natureza e a forma como ela influi na viagem dos restos mortais do apóstolo de Jerusalém à Península Ibérica, como apresentado tanto pelo Papa Calisto quanto pelo Papa Leão.

\footnotetext{
${ }^{6}$ Bíblia Sagrada. São Paulo: Paulinas Editora, 2005, Mc. 1, 19-20.

${ }^{7}$ Liber Sancti Iacobi, p. 384.

${ }^{8}$ Ibidem, p. 384.
}

Revista Vernáculo n. ${ }^{\circ} 43$ - primeiro semestre/2019

ISSN 2317-4021 
Ambos defendem que o corpo de São Tiago fora retirado de Jerusalém por seus discípulos e colocado em um barco a fim de ser sepultado em outro local. As condições ambientais no percurso em mar são em ambos os relatos favoráveis, já que no primeiro os apóstolos dão graças por não ter ocorrido-lhes nenhuma colisão com as rochas e nem terem sido vítimas de violentas ondas ou ataques de piratas $^{9} \mathrm{e}$ no segundo enfatizam-se as boas condições dos ventos e a tranquilidade das ondas $^{10}$. Em terra, no entanto, há contradição, pois no relato do Papa Calisto a viagem é associada ao sacrifício, perspectiva medieval de penitência, havendo diversos obstáculos, dentre eles animais ferozes, hereges e seres fantásticos - embora os discípulos de São Tiago sempre vencessem tais barreiras com o auxílio da água, seja pela correnteza que leva os inimigos, seja pela água benta que purifica a terra - enquanto no relato do Papa Leão a procura pelo local de sepultamento é, desde o início, livre de qualquer perigo. Indo ao encontro da primeira versão, Adeline Rucquoi ressalta a presença de um dragão que vivia em um monte da Galiza e que fora vencido pelos discípulos de São Tiago, conforme relatado no livro III do Codex, destacando-se, uma vez mais a vitória dos justos. ${ }^{11}$

O "maravilhoso" atingiu muitos aspectos da vida do homem do século XII e XIII, independente da sua posição social,

\footnotetext{
${ }^{9}$ Ibidem, pp. 388-389.

${ }^{10}$ Ibidem, p. 395.

${ }^{11}$ RUCQUOI, Adeline. La percepción de lanaturaleza em la alta Edad Media. In: Natura i desenvolupament. El medi ambient a l'Edat Mitjana, Lleida. PagèsEditors. 73-98, 2007, p. 84.
}

Revista Vernáculo n. ${ }^{\circ} 43$ - primeiro semestre/2019

ISSN 2317-4021 
porém o que nos traz mais interesse refere-se ao maravilhoso geográfico, as ilhas da cartografia medieval, os habitantes das terras maravilhosas, quer monstros humanos ou animais imaginários, o maravilhoso bíblico imaginado na Terra, o maravilhoso literário a descrever terras sobrenaturais. $^{12}$

Percebe-se a relevância da construção narrativa épica a respeito da jornada sob a vista de sua promoção. O Guia, ao divulgar a qualidade dos caminhos, revela a interligação entre o maravilhoso e o real, sempre inerentes, ainda que seja possível notar, já nesse período, uma emergente preocupação com a aproximação à geografia empírica, com a descrição de espécies e paisagens.

Para recuperar la percepción sensible, em el plano intelectual, fue necessário realizar uma interpretación y asimilación de lãs doctrinas de Aristóteles, tarea que será llevada a cabo, a partir delsiglo XIII, por agostinianos, como san Buenaventura (1221-1274), quien empezó a hacer passar lafe por el filtro de larazón, dirigiéndose de nuevo hacia la contemplación del mundo. ${ }^{13}$

\section{Peregrinação}

Após a morte de São Tiago e o encontro do local onde o corpo deveria ser enterrado, os discípulos reduzem os restos mortais do apóstolo a pó e o enterram, construindo em cima do sepulcro uma igreja de dimensões reduzidas, mas contendo um adornado altar. ${ }^{14}$ No século

12 CARVALHO, Márcia Siqueira de. Geografia e Imaginário na Idade Média, $R A E^{\prime} G A$, Curitiba. Boletim do Departamento de Geografia da Universidade Federal do Paraná. 1(1): 45-60,1998, pp. 48-49.

${ }^{13}$ MADERUELO, Javier. El paisaje. Génesis de un concepto. Madrid: Abada Editores, 2005, p. 81 ..

${ }^{14}$ LiberSanctilacobi, pp. 392 e 394.

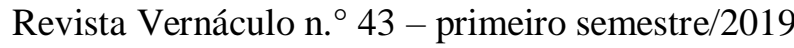

ISSN $2317-4021$ 
IX, após ser tomado, ou protegido, segundo os discípulos ${ }^{15}$, pela natureza que crescia ao redor e pelo aparente esquecimento por parte dos que conheciam sua localização, o sepulcro de São Tiago é encontrado. Segundo Fernando López Alsina, as pessoas que viviam próximas ao local de sepultamento relataram ter visto luzes e anjos dentro do bosque e, avisado de tais acontecimentos, Teodomiro, bispo de Iria, dirige-se à região para verificar o que de fato havia no local. ${ }^{16}$ Em meio às árvores e à umidade do bosque é que Teodomiro encontra o sepulcro no qual estariam as relíquias do santo apóstolo de Cristo, enviando logo a notícia ao rei, Alfonso II, o Casto.

Lugar de eminente manifestação do locusagrestis $^{17}$, o bosque, tal como o mar, aparece na hagiografia de São Tiago como meio que o acolhe e acolhe suas relíquias, onde a natureza uma vez mais agiria em conformidade com a proteção divina, ressaltando a magnanimidade da figura do santo e contrapondo-se à perspectiva famigerada do bosque como casa de seres desconhecidos e esconderijos de ladrões.Como

${ }^{15}$ Ibidem, p.394

${ }^{16}$ LÓPEZ ALSINA, Fernando. La Ciudad de Santiago de Compostela em la Alta Edad Media. Santiago de Compostela: Universidad de Santiago de Compostela, 2014, p. 113.

${ }^{17}$ Caracteriza-se pelo desconhecido, que dá lugar, por sua vez, ao imaginário, cuja atuação de elementos naturais, maravilhosos ou não, atentaria contra a vida humana. Contrapondo-se ao lócus amoenus, o lócus agrestis apresenta-se ainda como a manifestação da ira divina sobre os homens ou como sinal de futuros relevantes acontecimentos.

Revista Vernáculo n. ${ }^{\circ} 43$ - primeiro semestre/2019

ISSN 2317-4021 
ressalta o autor ${ }^{18}$, o intuito inicial do rei e do bispo não seria propriamente habitar o local descoberto, mas fomentar um culto religioso, uma vez que, como é apresentado no Codex Calixtinus, não havia em toda Hispania maior motivo de veneração cristã. Nesse contexto, a peregrinação aparecia como um trunfo político, religioso e econômico. Iniciam-se as construções da Catedral de São Tiago sobre a antiga capela do sepulcro, que seria a sede do bispado, e o bosque presente naquela região foi certamente reduzido a fim de abrir espaço inicialmente para a Catedral e posteriormente para a urbe que ali se formaria. A natureza protetora dava espaço ao que seria um dos maiores centros de peregrinação do mundo.

López Alsina destaca a distribuição de pseudo epístolas pelo Ocidente, que relatavam a descoberta do sepulcro em 865 e estimulavam o culto ao apóstolo. ${ }^{19}$ A peregrinação a Santiago de Compostela teria alí sua origem. O conhecimento da notícia fomentou a ocupação do território ao longo dos anos seguintes, sendo que no século $\mathrm{X}$ já seria possível encontrar uma urbe em sua plenitude. Destacam-se duas regiões na formação da cidade de Compostela - termo que significa "campo de estrelas" - de acordo com López Alsina: o intus, onde se localizavam os edifícios e se destacaria o espaço urbano, e o foris, espaço constituído por prados, bosques ou terras de cultivo de

${ }^{18}$ LÓPEZ ALSINA, Fernando. La Ciudad de Santiago de Compostelaenla Alta Edad Media. Santiago de Compostela: Universidad de Santiago de Compostela, 2014, p. 144.

${ }^{19}$ Ibidem, p. 194.

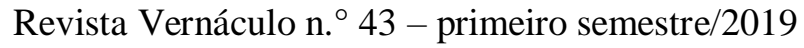

ISSN $2317-4021$ 
onde saía a fonte de subsistência da população. O termo villa era também usado por clérigos para designar a região. ${ }^{20} \mathrm{O}$ lugar que constituía o chamado locus rural passa a abrigar, tanto provisória quanto definitivamente os peregrinos que para lá se dirigiam, contribuindo para a domesticação da natureza local e expansão do espaço urbano.

\section{Natureza peregrina}

Simultaneamente à divulgação da descoberta do sepulcro apostólico, uma nova imagem de São Tiago é apresentada aos fiéis. O pescador que viveu às margens dos rios a fim de conseguir seu sustento dá lugar ao guerreiro, que luta e intercede pelos cavaleiros nas guerras santas, uma mudança que aproximava o santo apóstolo à realidade do povo hispânico, embora sempre houvesse aqueles que defendiam a permanência da imagem do pescador, por sua origem. Uma terceira imagem atribuída ao apóstolo é a do próprio peregrino que, com seu cajado na mão, vence os obstáculos físicos, simbólicos e espirituais e caminha em direção à salvação.

O sentido da peregrinação medieval era a penitência, a redenção dos pecados. Os árduos caminhos físicos indicavam avanço espiritual e o sofrimento era tido como um valor. A crença de que a peregrinação a Santiago de Compostela traria a absolvição de todos os pecados levou habitantes de toda Europa a sair de suas regiões com destino a

${ }^{20}$ Ibidem, p. 205.

Revista Vernáculo n. ${ }^{\circ} 43$ - primeiro semestre/2019

ISSN 2317-4021 
Compostela, percorrendo caminhos diversos para tanto.A fim de dar assistência aos peregrinos e gerar a economia local, algumas vilas e cidades foram criadas ao longo dos caminhos que ligavam a cidade sepulcral aos demais reinos da Europa, especialmente a partir do século XI. No século XII, com o aumento no número de peregrinos é que Aymerico Picaud escreve o Guia do Peregrino, livro V do Liber Sancti Iacobi, tendo por finalidade informar o peregrino sobre o que encontraria no percurso e alertá-lo para os possíveis perigos. A peregrinação estava, no entanto, longe de ser uma missão fácil, devendo o homem vencer os desafios e o desconhecido que lhe eram apresentados, somente conseguindo, por vezes, por meio da fé. Como afirma Carlos Barros, "Aquello que elhombre no domina com sues fuerzo, la técnica y laciencia medieval, lohace por medio de una religión monista, sincrética y antropocéntrica.” e complementa: “(...) El hombre apela a la providencia cuando la relación de fuerzas le es contraria (...). ${ }^{, 21}$

Ao longo do Guia, o peregrino é avisado dos caminhos, cidades e povos que poderão ser encontrados na jornada e quais os lugares que melhor o receberão. No capítulo VI o autor fala sobre os rios que estarão no percurso de Port de Cize e Somport até Santiago, citando “(...) El salud ablerío llamado Aragón, que riega España.” e “(...) el

${ }^{21}$ BARROS, Carlos. La humanización de lanaturalezaenlaEdad Media, EM. 169-193, 1999, p. 178.

Revista Vernáculo n. ${ }^{\circ} 43$ - primeiro semestre/2019

ISSN 2317-4021 
sano río que por muchos es llamado Runa y baña Pamplona."22 e alerta aos viajantes a respeito de quais rios devem ser evitados, como o Salado que passa por Lorca: "Allí guárdate de beber ni tú ni tu caballo, pues El río es mortífero." 23 , assim como os rios que passam pelas vilas de Los Arcos e Cuervas, que têm águas impuras e nocivas a homens e animais, ou ainda os rios que vão de Estella a Logroño, pois assim como sua água não é saudável, a carne do peixe que ali vive, chamado vulgarmente por barbo, segundo o autor, é igualmente nociva, e afirma ainda que: "Todos los pescados y carnes de vaca y cerdo de toda España y Galicia producen enfermedades a los extranjeros."24. Há também os bons rios, como o Ega, que passa por Estella, o Sar, que passa entre o Monte Del Gozo e Santiago, o Burbia, que corre pela ponte de Villa franca, dentre outros. ${ }^{25}$

No capítulo VII o autor se dedica a falar sobre os povos e lugares por onde passarão os peregrinos. A terra de Burdeos, por exemplo, é rica em mel, milho e porcos, embora seja pobre em rios, peixes e pão, e o autor ainda alerta: "Y si no miras atentamente donde pisas, em la arena del mar, que allí abunda, rápidamente te hun dirás hasta la rodilla.". ${ }^{26}$ Em Gascuña há, ao contrário, bosques, prados, boas fontes e rios navegáveis. $\mathrm{O}$ autor destaca ainda a presença de um monte alto no país Vasco, pelo qual se transportam coisas de uma terra a outra

\footnotetext{
${ }^{22}$ LiberSanctilacobi, p. 539.

${ }^{23}$ Idem.

${ }^{24}$ Ibidem, p. 540.

${ }^{25}$ Ibidem, p. 541.

${ }^{26}$ Ibidem, p. 544.
}

Revista Vernáculo n. ${ }^{\circ} 43$ - primeiro semestre/2019

ISSN 2317-4021 
e de onde, segundo se afirma, é possível avistar os mares britânico e ocidental, bem como as terras de Castela, Aragão e Francia. No alto de tal monte há um lugar chamado "Cruz de Carlos Magno" onde os peregrinos podem rezar, sendo também onde Carlos Magno teria rezado clamando São Tiago em batalha. ${ }^{27}$ Neste mesmo monte o autor diz haver um vale chamado Varcarlos, no qual Carlos Magno teria acampado junto de seu exército. Nas regiões de Castilla e Campos encontram-se ouro e prata, além de carne, mel e árvores escassas, diferentemente da terra dos galegos onde há bosques, rios agradáveis, muitos prados e ricos pomares, onde o peregrino será bem servido de boas frutas e exuberante natureza. ${ }^{28}$

Por definição, o peregrino seria:

(...) todo aquele que se encontrava fora do seu domicílio ou provinha de uma terra estranha. Acima de tudo, o 'peregrino' era o 'estrangeiro', o exótico, o estranho, o que viaja, o que corre as terras alheias... Peregrinatio, portanto, era uma grande viagem, e, no infinito, peregrinati era viajar por lugares distantes e desconhecidos. ${ }^{29}$

Assim, peregrinar seria entregar-se ao desconhecido e ser o desconhecido, ainda que em seu próprio reino. Além disso, o desconhecido da paisagem, sempre surpreendente, intensificava-se para

${ }^{27}$ Ibidem, p. 547.

${ }^{28}$ Ibidem, p. 551.

${ }^{29}$ LIMA, Marcelo Pereira. Muito mais do que um modo de "orar com os pés" - As peregrinações jacobeias medievais em textos legislativos e normativos. In: FRANÇA, Susani Silveira Lemos, NASCIMENTO, Renata Cristina de Sousa, LIMA, Marcelo Pereira. Peregrinos e Peregrinações na Idade Média. Petrópolis: Editora Vozes, 2017, p. 136.

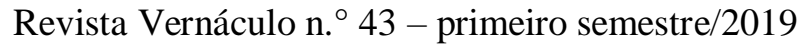

ISSN 2317-4021 
o estrangeiro que vinha de regiões distantes e que lidava, não apenas com um espaço geográfico, urbano e climático distinto, mas com gente, modos e línguas distintas. Nesse sentido, as vestes dos peregrinos não apenas os auxiliavam na proteção frente aos desafios e variações climáticas ao longo do caminho, mas os identificava e distinguia. A observação feita por Simon Schama - ainda que não aplicada especificamente à peregrinação, mas ao conhecimento da natureza em determinada localidade - acerca da vivência local em contrapartida ao estrangeiro, ilustra bem a ideia do exótico ao longo da jornada:

A rede de caminhos que cruzava uma paisagem podia desorientar rapidamente os moradores da cidade, mas para os habitantes locais possuía numerosos marcos distintivos: pedras cobertas de hepáticas; árvores antigas fulminadas por um raio; troncos e raízes que assumiam formas sugestivas o bastante para ganhar apelidos; riachos serpenteantes, lagoas e pântanos; outeiros e taludes; as ruínas de velhas casas e muros; as cinzas de um braseiro. ${ }^{30}$

Não se trata, com o Guia do Peregrino, de evitar o sentido penitencial da peregrinação, que edificaria espiritualmente o viajante, mas de possibilitar ao peregrino a decisão da entrega e, principalmente, garantir sua chegada ao destino. A peregrinação passava, gradativamente, a movimentar setores econômicos e urbanos que atuariam ao longo do caminho, com albergues, hospitais, dentre todos os pontos de suporte ao peregrino que ofereciam-lhes abrigo e um local onde pudessem fazer suas orações, como o Monastério de Santa Maríala

${ }^{30}$ SCHAMA, Simon. Paisagem e Memória. São Paulo: Companhia das Letras, 1996, p. 115.

Revista Vernáculo n. ${ }^{\circ} 43$ - primeiro semestre/2019

ISSN 2317-4021 
Real de Las Huelgas, em Burgos, além das iniciativas na própria cidade de Santiago de Compostela, como a construção da Catedral frente à necessidade de um templo maior para comportar os fiéis, venda de broches e outros objetos estampados com uma concha,símbolo do apóstolo e da cidade, ${ }^{31}$ além da ampliação de hospedagens, fazendo de Santiago de Compostela um dos grandes centros de peregrinação no medievo. A respeito dessa cidade, Aymerico Picaud destaca sua localização entre os rios Sar e Saravela, além da presença de uma fonte dentro da cidade, a fonte de São Tiago, da qual jorra uma água pura e refrescante, cuja origem ou destino ninguém conhece. ${ }^{32} \mathrm{Tem}-\mathrm{se}$ aí, a base para mais um dos atrativos miraculosos da cidade. A Catedral de Santiago, edificada com pedras, apresenta esculturas como, por exemplo, as da porta ocidental, que ilustram bem a influência do meio natural no âmbito religioso da cidade. Ali, encontram-se as representações de animais, flores, homens no labor de seus diferentes ofícios, santos e anjos.Acerca da representatividade da natureza na arte, e logo na das catedrais, afirma Javier Maderuelo:

El simbolismo floral medieval, que es muy complejo, se extendía hasta $\mathrm{El}$ efecto curativo de las plantas, que dependia más de la advocación a tal virgen o santo que a sus cualidades terapêuticas. Con estas aplicaciones

\footnotetext{
${ }^{31}$ Um dos porquês em ter a concha por símbolo de São Tiago Maior seria um dos milagres deste santo, no qual São Tiago resgata do mar um cavaleiro coberto por conchas. A concha, além de elemento que remete ao meio marítimo do traslado e dos milagres, torna-se instrumento de uso do peregrino para apanhar água.

${ }^{32}$ Liber Sancti Iacobi, p. 587.
}

Revista Vernáculo n. ${ }^{\circ} 43$ - primeiro semestre/2019

ISSN $2317-4021$ 
simbólicas de la farmacopea, sinduda, se pretendia más el com suelo del alma que lãs alud del cuerpo. ${ }^{33}$

Após a difusão da descoberta do sepulcro apostólico e principalmente com o início das peregrinações a Compostela, alguns milagres foram atribuídos a São Tiago e descritos pelo Papa Calisto II no Liber Sancti Iacobi, sendo que grande parte deles têm relações com o mar. Um exemplo consisteno milagre referente a alguns peregrinos que navegavam à Terra Santa. Sendo abordado por sarracenos e caindo no fundo do mar, o marinheiro passa a clamar pela intercessão de São Tiago. "Al instante seleaparecióel santo Apóstolenlo profundo del mar y, tomándole de la mano, lo volvió a la nave sano y salvo. " E por fim, o autor afirma ter dito o santo apóstolo: "No soy El Dios del mar, sino um siervo del Dio sdel mar, que auxilio a los que enpeligro me llaman, tanto enel mar como em latierra, según Dios quiere."34 Tal milagre expressa os perigos naturais e humanos que encontravam os navegantes em suas viagens - como já discutido - as quais deveriam “(...) sortear numerosos riesgos, por lo que el viajero, más que em los marineros, estaba em las manos de Dios." ${ }^{35}$, ou do santo; expressa ainda a prática de navegar em peregrinação, tanto a Santiago de Compostela quanto à Terra Santa, viagem "ao centro da Terra" - segundo os mapas-múndi do período, como o de Ebstorf - que, em equivalência à peregrinação à pé, detinha desafios igualmente tratados pela natureza.

${ }^{33}$ MADERUELO, Javier. P. 82.

${ }^{34}$ Ibidem, pp. 343-344.

${ }^{35}$ MOLINA MOLINA, ÁngelLuis. P. 121.

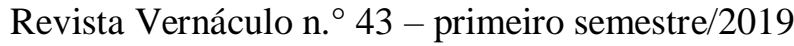

ISSN $2317-4021$ 


\section{Considerações finais}

Se o que importa não é necessariamente o destino, mas o caminho, os peregrinos medievais já tinham conhecimento disso ao fazerem das peregrinações um motivo devocional à parte do destino e todos seus atrativos, especialmente as relíquias. Além de contribuir para um melhor desempenho da viagem, o Guia do Peregrino configura-se como suporte cada vez mais necessário ao peregrino, função que também seria atribuída aos relatos de viagem acerca da peregrinação, especialmente a partir do século XIV, quando o realismo geográfico passa a integrá-los ${ }^{36}$. A natureza, por sua vez, dá vida ao sentido da peregrinação, e com o auxílio dela é possível expressar a fé por meio de cultos e milagres, construir uma identidade, uma crença e uma cultura. $\mathrm{O}$ ambiente natural na Idade Média, especialmente relacionado à peregrinação a Santiago de Compostela com tudo que a envolve, é construído por um lado pelo imaginário do período, com a idéia de pecado e sofrimento onde a natureza aparece como inimiga, e por outro lado pela visão de um ambiente que acolhe e auxilia o homem. Traz-se à tona uma visão maniqueísta como forma de se perceber o ambiente natural.

${ }^{36}$ FRANÇA, Susani Silveira Lemos. Peregrinos e centros de peregrinação. In: FRANÇA, Susani Silveira Lemos, NASCIMENTO, Renata Cristina de Sousa, LIMA, Marcelo Pereira. Peregrinos e Peregrinações na Idade Média.Petrópolis: Editora Vozes, 2017, p. 22.

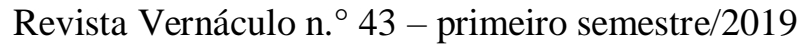

ISSN $2317-4021$ 
Monges, laicos, camponeses e nobres, tais como Guilherme V, duque da Aquitânia, foram todos peregrinos a caminho de Compostela. A peregrinação, mais que um impulso à fé, cujos olhos voltam-se à presença de São Tiago Maior em Compostela, é em si a própria fé por meio do caminho, construído por Deus em sua integridade. A natureza, criatura tal como o ser humano, apresenta-se, por meio de sua dualidade, o próprio Criador, que insere, com suas próprias mãos, as pedras, árvores, rios e animais que compõem todos os caminhos que levam a Santiago de Compostela, fazendo do caminhar um momento de contato com Ele. Assim, “(...) Dios es verdaderamente todo lo que verdaderamente es, porque el mismo crea todos los seres y se crea en todos, como dice San Dionisio Areopagita. ${ }^{" 37}$ A natureza aliava-se aos sentidos humanos, identificando o peregrinar aos seus sons, cores, formas, aromas, texturas e sabores. ${ }^{38} \mathrm{~A}$ paisagem natural, misto de beleza que impulsiona louvores a Deus e perigos que provam o homem, possibilita o sentido da peregrinação, onde religiosidade, imaginário, ciência e poder se entrecruzam.

${ }^{37}$ RAÑA DAFONTE, César. Natura optima parens. La naturaleza em El siglo XII, Revista Española de Filosofía Medieval. 16: 43-56, 2009, p. 49.

${ }^{38}$ DÍAZ DUCKWEN, María Luján. ¿Enqué forma puede una hagiografía transmitir sonidos? El caso de lavitas sanctorum patrumemeretensium. In: RODRÍGUEZ, Gerardo, CORONADO SCHWINDT, Gisela (org.). Abordajes Sensoriales del Mundo Medieval. Mar del Plata: Universidad Nacional de Mar del Plata. Facultad de Humanidades, GIEM, 2017, pp. 15-30.

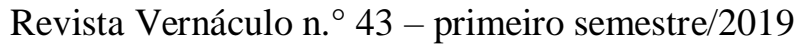

ISSN $2317-4021$ 


\section{Referências}

\section{Fontes}

BÍBLIA SAGRADA. São Paulo: Paulinas Editora, 2005.

LIBER SANCTI IACOBI. CODEX CALIXTINUS.Trad. Abelardo Moralejo, Casimiro Torres, JulioFeo. Ed. María José García Blanco. Xunta de Galicia, 2014.

\section{Bibliografia}

AZNAR VALLEJO, Eduardo. El mar: fuente de conflictos y exigencia de paz, Edad Media. 11: 63-89, 2010.

BARROS, Carlos. La humanización de lanaturalezaenlaEdad Media, EM. 169-193, 1999.

CARVALHO, Alessandra Izabel de, LAVERDI, Robson, SILVA, Danusa de Lourdes Guimarães da. A dimensão ambiental do conhecimento histórico: entrevista com José Augusto Pádua, Revista de História Regional. 19(2): 457-484, 2014.

CARVALHO, Márcia Siqueira de. Geografia e Imaginário na Idade Média, $R A E^{\prime} G A$, Curitiba. Boletim do Departamento de Geografia da Universidade Federal do Paraná. 1(1): 45-60,1998,

CHAFUEN, Alejandro. El pensamento católico medieval sobre los bosques, losanimales y elsubsuelo, Revista Cultura Económica. 31(86): 7-18, 2013.

DÍAZ DUCKWEN, MaríaLuján. ¿Enqué forma puede una hagiografía transmitir sonidos? El caso de lavitas sanctorum patrumemeretensium. In: RODRÍGUEZ, Gerardo, CORONADO SCHWINDT, Gisela (org.). AbordajesSensorialesdel Mundo Medieval. Mar del Plata: 
Universidad Nacional de Mar del Plata. Facultad de Humanidades, GIEM, 2017.

FERNÁNDEZ GONZÁLES, Etelvina. Los árboles no dejan ver el bosque. Apreciaciones plásticas e iconográficas em laEdad Media, Cuadernos del CEMYR. 21: 11-48, 2013.

FRANÇA, Susani Silveira Lemos. Peregrinos e centros de peregrinação. In: FRANÇA, Susani Silveira Lemos, NASCIMENTO, Renata Cristina de Sousa, LIMA, Marcelo Pereira. Peregrinos e Peregrinações na Idade Média. Petrópolis: Editora Vozes, 2017.

KESSELRING, Thomas. O conceito de natureza na história do pensamento Ocidental, Episteme, Porto Alegre. 11: 153-172, 2000.

LEBRERO COCHO, Jorge. Hidrofobia medieval: miedos y peligros vinculados al água em la literatura castellana del XV, Medievalismo. 25: 261-284, 2015.

LIMA, Marcelo Pereira. Muito mais do que um modo de "orar com os pés" - As peregrinações jacobeias medievais em textos legislativos e normativos. In: FRANÇA, Susani Silveira Lemos, NASCIMENTO, Renata Cristina de Sousa, LIMA, Marcelo Pereira. Peregrinos e Peregrinações na Idade Média. Petrópolis: Editora Vozes, 2017.

LÓPEZ ALSINA, Fernando. La Ciudad de Santiago de Compostela em la Alta Edad Media. Santiago de Compostela: Universidad de Santiago de Compostela, 2014.

MADERUELO, Javier. El paisaje. Génesis de un concepto. Madrid: Abada Editores, 2005.

MOLINA MOLINA, Ángel Luis. Los viajes por mar em la Edad Media, Cuadernos de Turismo.5: 113-122, 2000.

PASTOUREAU, Michel. Una historia simbólica de la Edad Media occidental. Madrid: Katz Editores, 2013.

Revista Vernáculo n. ${ }^{\circ} 43$ - primeiro semestre/2019

ISSN 2317-4021 
RAÑA DAFONTE, César. Natura optima parens. La naturaleza em el siglo XII, Revista Española de Filosofía Medieval. 16: 43-56, 2009.

RIBEIRO, Maria Eurydice de Barros. Entre saberes e crenças: o mundo animal na Idade Média, História Revista, Goiânia. 18(1): 135-150, 2013.

RUCQUOI, Adeline. La percepción de la naturaleza em la alta Edad Media. In: Natura $i$ desenvolupament. El medi ambient a l'Edat Mitjana, Lleida. Pagès Editors. 73-98, 2007.

SCHAMA, Simon. Paisagem e Memória. São Paulo: Companhia das Letras, 1996.

SOUZA, Armênia Maria de, NASCIMENTO, Renata Cristina de Sousa (org.). Mundos Ibéricos: territórios, gênero e religiosidade. São Paulo: Alameda, 2017.

VARANDAS, Angélica. A Idade Média e o Bestiário, Medievalista. Instituto de Estudos Medievais. 2(2): 1-53, 2006.

Recebido em 20/08/18 aceito para publicação em 04/12/18

Revista Vernáculo n. ${ }^{\circ} 43$ - primeiro semestre/2019

ISSN 2317-4021

92 